\title{
THE NATURE OF THE EXCITED STATES OF p-NITRO-N,N-DIMETHYLANILINE
}

\author{
J. DOBKOWSKI, J. HERBICH and J. WALUK \\ Institute of Physical Chemistry, Polish Academy of Sciences, Warsaw, Poland
}

\section{J. KOPUT}

Adam Mickiewicz University, Poznań, Poland

\section{W. KÜHNLE}

Max-Planck-Institut für Biophysikalische Chemie, Göttingen, Fed. Rep. Germany

Received 17 March 1989

Accepted 6 July 1989

Contrary to numerous derivatives of p-substituted $\mathrm{N}, \mathrm{N}$-dimethyl-aniline, $\mathrm{p}$-nitro- $\mathrm{N}, \mathrm{N}$-dimethylaniline, does not form the TICT state. This behaviour is predicted by INDO/S calculations. The calculations also reveal an important role of the Coulomb interaction term in the evolution of intramolecular charge-transfer excited-state energy upon twisting of the dimethylamino group.

\section{Introduction}

During the last ten years it was discovered that numerous para-substituted aromatic molecules of the type D-Ar-A (where D/A represent an electron donor/acceptor group and $\mathrm{Ar}$ an aromatic ring system) undergo relaxation in the excited singlet state to a highly polar state, preferentially in fluid polar solvents, and the emission occurs from two different excited states. Numerous attempts were published in order to explain the experimental results [1-6]. However, the twisted intramolecular charge transfer (TICT) state formation hypothesis [7] seems to be better founded than the other proposals to explain this behaviour (see fig. 1).

The aim of our studies is to investigate whether p-nitro-N,N-dimethylaniline (I) in a polar solvent shows a relaxation to the TICT state. For the sake of comparison with I, three model compounds were synthesized: II, with the dialkyl amino group fixed, III and IV, with the dialkylamino or nitro group twisted around the respective $\mathrm{N}-\mathrm{C}$ bond (see fig. 2).

The TICT state formation of I seems to be
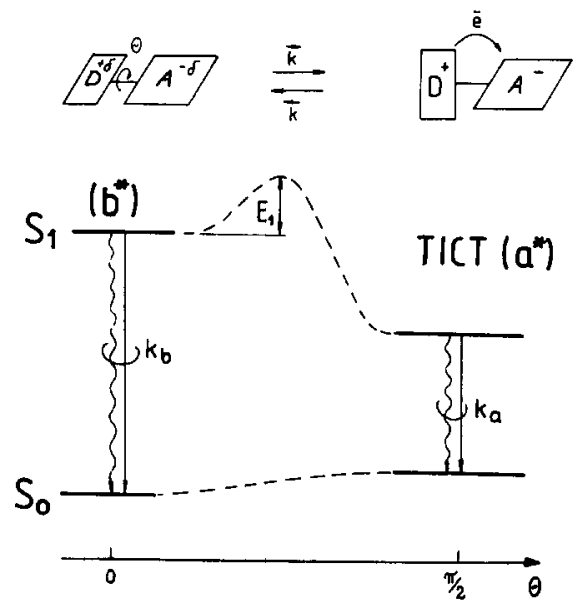

Fig. 1. TICT model. Schematic cross-section of the ground state and lowest excited singlet state potential hypersurfaces along the reaction coordinate represented here by the twist angle $\theta$.

0022-2313/89/\$03.50 을 Elsevier Science Publishers B.V.

(North-Holland Physics Publishing Division) 
<smiles>O=[N+][O-]</smiles><smiles>CN1CCc2cc([N+](=O)[O-])ccc21</smiles><smiles>CN(C)c1c([N+](=O)[O-])cc([N+](=O)[O-])cc1[N+](=O)[O-]</smiles><smiles>O=[N+]([O-])c1cc([N+](=O)[O-])cc([N+]([O-])=[N+][O-])c1</smiles>

I
III IV

Fig. 2. Formulae of the studied compounds.

possible from the thermodynamical point of view. The linear correlation of the TICT fluorescence maxima with the difference of the oxidation potential of the donor and the reduction potential of the acceptor group was found for a series of molecules emitting TICT fluorescence [8].

The energy of the TICT fluorescence may be estimated as [8]

$h c \tilde{\nu}=E_{1 / 2}^{\mathrm{ox}}(\mathrm{D})-E_{1 / 2}^{\mathrm{red}}(\mathrm{A})+E_{\text {coul }}-E_{\text {dest }}$,

where $E_{1 / 2}^{\mathrm{ox}}(\mathrm{D}), E_{1 / 2}^{\mathrm{red}}(\mathrm{A})$ are the polarographic half-wave potentials of one electron oxidation of the donor (D), or reduction of the acceptor (A), respectively, and $E_{\text {coul }}$ is the coulombic energy of bringing the opposite charges to the fixed distance. The entropy term is expected to be roughly constant within the considered series of p-derivatives of $\mathrm{N}, \mathrm{N}$-dimethylaniline and was neglected [8].

The emission from the highly polar TICT state leads to the Franck-Condon (FC) nonpolar ground state of the twisted conformer. This FC state is more energetic than the solvent-equilibrated ground state by the destabilisation energy, $E_{\text {dest }}$.

For different para-substituted dimethylanilines $E_{1 / 2}^{\mathrm{ox}}(\mathrm{D}), E_{\text {coul }}$ and $E_{\text {dest }} \approx$ const, therefore the observed TICT fluorescence maxima were correlated with the reduction potentials of acceptors only (fig. 3, table 1).

This correlation allows us to evaluate the energy of the fluorescence maximum emitted from the hypothetical TICT state created by internal rotation of the $\mathrm{N}\left(\mathrm{CH}_{3}\right)_{2}$ group; the estimated value: $E_{\mathrm{TICT}}=10600-12000 \mathrm{~cm}^{-1}$.

For nitro compounds, in many cases, the efficient photoreactions take place and consequently, the new absorption and emission bands are ob-

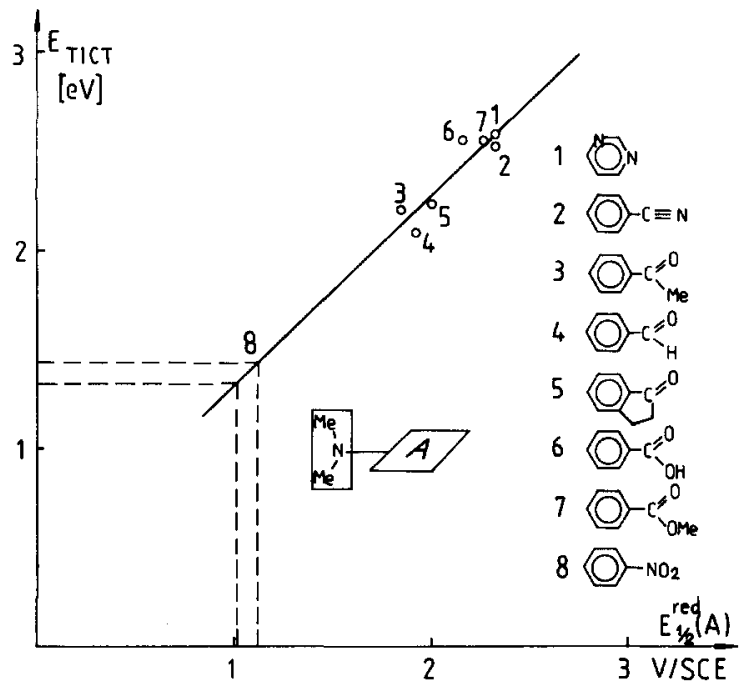

Fig. 3. Energy of the TICT fluorescence maximum for the compounds $1-7$ in acetonitrile solutions against the polarographic half-wave potentials of one-electron reduction of the acceptors $(\mathrm{A})$ in acetonitrile or dimethylformamide solutions, correlation coefficient $r^{\prime}=0.91-0.94$. Vertical dashed lines indicate the region of the measured values of $E_{1 / 2}^{\text {red }}(\mathrm{A})$ for I (table 1). According to the correlation (points 1-7) the expected emission maximum of the hypothetical TICT state of I is indicated by horizontal dashed lines.

Table 1

Polarographic half-wave potentials of one-electron reduction of acceptors (A), in V vs SCE, in acetonitrile or dimethyl formamide solution, and energies of the fluorescence a transition $\left(h c \tilde{\nu}_{\mathrm{a}}\right)$ in acetonitrile solutions

\begin{tabular}{|c|c|c|c|c|c|}
\hline No. & Acceptor & $\begin{array}{l}-E_{1 / 2}^{\mathrm{red}}(\mathrm{A}) \\
(\mathrm{V})\end{array}$ & Ref. & $\begin{array}{l}h c \tilde{\nu}_{\mathrm{a}} \\
(\mathrm{eV})\end{array}$ & Ref. \\
\hline 1 & pyrimidine & 2.34 & 9 & 2.60 & $10^{\text {a) }}$ \\
\hline 2 & benzonitrile & 2.35 & 12 & 2.57 & 1 \\
\hline 3 & acetophenone & 1.87 & 9 & 2.24 & 13,14 \\
\hline 4 & benzaldehyde & 1.93 & 9 & 2.08 & 14 \\
\hline 5 & 1-indanone & 2.01 & 15 & 2.27 & 14 \\
\hline 6 & benzoic acid & $2.17,2.24$ & 9 & 2.58 & 16 \\
\hline 7 & methyl benzoate & $2.29,2.32$ & 9 & 2.58 & 16 \\
\hline 8 & nitrobenzene & $1.01,1.13$ & 9 & & \\
\hline
\end{tabular}

a) Recently it has been discovered the TICT fluorescence of the 4-dimethylamino-pyrimidine (DMAP) to be observed only in polar protic solvents [11]. For the ortho-methylated derivative of DMAP (5-Me-DMAP) the observed maximum of the TICT fluorescence in ethanol is at the same spectral position as for DMAP, that is why we can use the $h c \tilde{v}_{a}$ value measured in acetonitrile for the 5-Me-DMAP molecule. 
served [17]. In the case of I-IV, in our experimental conditions we did not observe any new detectable absorption or emission bands.

\section{Experimental and calculations}

p-Nitro-N,N-dimethylaniline (I) has been prepared according to Fitch [18a], and carefully separated from the $\mathrm{m}$-isomer.

1-Methyl-5-nitroindoline (II) (1.62 g) was prepared via 5-nitroindoline (5-NI) [18b] by the following methylation procedure: $1.64 \mathrm{~g} 5-\mathrm{NI}+0.8 \mathrm{~g}$ $\mathrm{Na}_{2} \mathrm{CO}_{3}$ anhydrous $+2.13 \mathrm{~g} \mathrm{CH}_{3} \mathrm{I}$ and $3 \mathrm{ml}$ of absolute methanol were refluxed for $12 \mathrm{~h}$. The residue after evaporation of the solvent was sublimed at $p=5$ Torr and $t=220^{\circ} \mathrm{C}$. The product was additionally purified by recrystallizations from chloroform $\left(\mathrm{mp} 126^{\circ} \mathrm{C}\right)$, and checked by MS.

$\mathrm{N}, \mathrm{N}$-2,6-tetramethyl-4-nitroaniline (III) was synthesized as described earlier [19].

p-nitro-3,5-N, $\mathrm{N}^{\prime}$-tetramethylaniline (IV) was prepared via $3,5, \mathrm{~N}, \mathrm{~N}^{\prime}$-tetramethylaniline [TMA] by the following nitration procedure: $1.5 \mathrm{~g}$ of TMA was dissolved in $20 \mathrm{ml}$ of concentrated sulphuric acid and $1.3 \mathrm{~g}$ of $\mathrm{NaNO}_{2}$ was added at $t=0^{\circ} \mathrm{C}$. After $2 \mathrm{~h}$ stirring at room temperature the solution was cooled and neutralized by $\mathrm{NH}_{3}$. The residue after filtration was crystallized from benzene.

I, II, III and IV were purified by sublimation, n-propanol (Merck, for fluorescence) was used without further purification. Luminescence measurements were done with the Jasny-type spectrofluorimeter [20].

The standard INDO/S method [21] was used for calculations of transition energies $(E)$, oscillator strengths $(f)$, dipole moments $(\mu)$ and electron charge distribution. All singly excited configurations lying below $10 \mathrm{eV}$ were taken into account in the CI procedure. The following values were used in the input geometries: $r_{\mathrm{CC}}$ (phenyl ring) $=$ $1.4 \AA, \Varangle \mathrm{CCC}=120^{\circ}, r_{\mathrm{CN}}$ (phenyl carbon-amino nitrogen) $=1.37 \AA, r_{\mathrm{NC}}$ (amino nitrogen-methyl carbon) $=1.5 \AA, r_{\mathrm{CN}}$ (phenyl carbon-nitro nitrogen $)=1.4 \AA, \quad r_{\text {NO }}=1.25 \AA, \quad r_{\mathrm{CC}}$ (phenyl carbon-acetyl carbon) $=1.47 \AA, r_{\mathrm{CO}}=1.2 \AA$, $r_{\mathrm{CC}}($ acetyl group $)=1.47 \AA, r_{\mathrm{NO}}($ nitroso group $)=$
$1.2 \AA, \nless \mathrm{CNO}=108^{\circ}[22], r_{\mathrm{CH}_{3}}$ (phenyl ring) $=1.08$

$\AA$, $r_{\mathrm{CH}}$ (methyl group) $=1.09 \AA$.

Two different input geometries were used:

(A) the "idealized" one with the above mentioned values of distances and angles,

(B) the one based on crystal structure data [23].

The calculations were performed for various angles of twisting of the dimethylamino group with respect to the phenyl ring: $0^{\circ}, 30^{\circ}, 60^{\circ}$, and $90^{\circ} ; \mathrm{sp}^{2}$ hybridisation of the amino nitrogen was assumed.

\section{Results and discussion}

\subsection{Low-temperature spectra}

Low-temperature luminescence spectra (fig. 4) of I and III in n-propanol are characterized by strong phosphorescence and weak fluorescence in contrast to II, which emits strong fluorescence and weak phosphorescence. These results suggest that $k_{\text {ISC }}$ for $\mathrm{p}-\mathrm{N}, \mathrm{N}$-dimethylnitroaniline and its derivatives strongly depends on the relative positions of the singlet and triplet states. Indeed, the first absorption-band of II is red shifted by $1000 \mathrm{~cm}^{-1}$ with respect to I and III. Kasha and Rawls [24a] discovered that the quantum yields of phosphorescence of aromatic amines depend on the twist angle of the $\mathrm{NMe}_{2}$ group. This mechanism can also play a role here; there is, however, no experimental evidence indicating the deviation from planarity in the case of p-nitro-N,N-dimethylaniline. For IV no detectable luminescence is observed.

The difference between fluorescence and phosphorescence excitation spectra of I (fig. 4) was first observed by McGlynn [24b] and ascribed to a very efficient intersystem crossing from $\mathrm{S}_{2}$ competing with internal conversion (IC) to $S_{1}$. Recently, the nature of the excitation-dependent luminescence of I was examined by Wild and his students [25]. Their results indicate that the anomalous luminescence behaviour of $I$ can be explained not only in terms of $k_{\text {ISC }}$ dependence on $\lambda_{\text {exc }}$ but may also be due to the subtle difference in the molecular environment and/or presence of different ground state conformers. The 


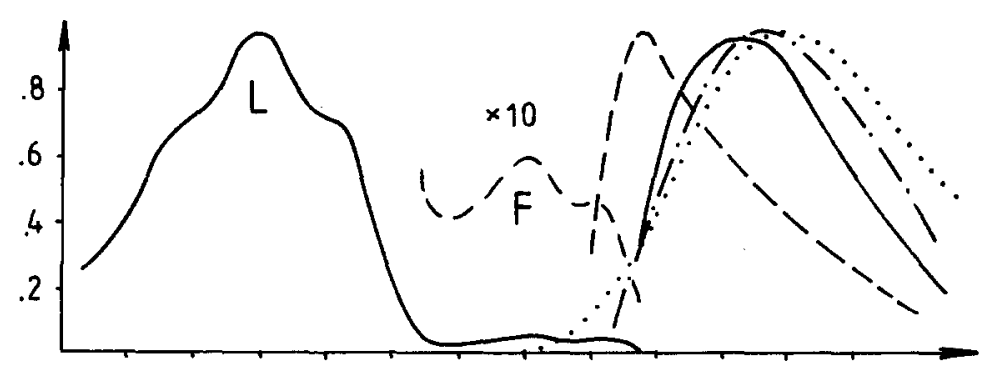<smiles>CN(C)c1ccc([N+](=O)[O-])cc1</smiles>

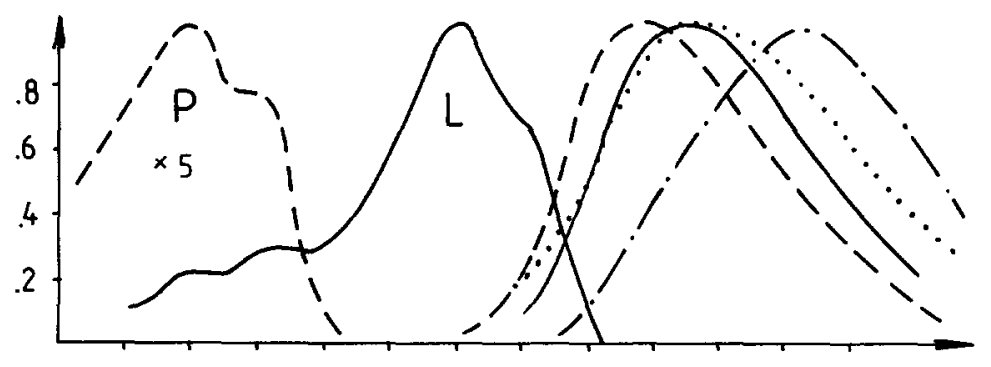<smiles>O=[N+]([O-])c1ccc2c(c1)CCN2O</smiles>

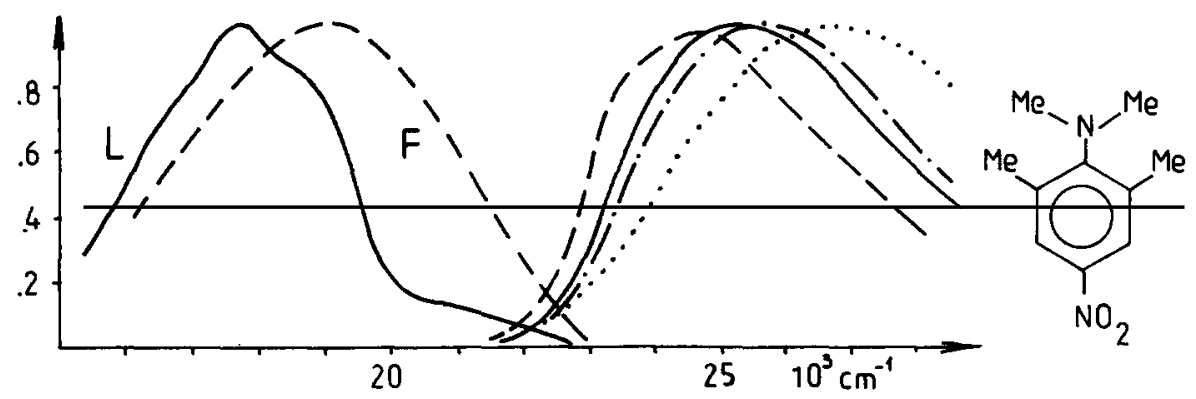

Fig. 4. Normalized low-temperature spectra of $\mathrm{I}-\mathrm{III}$ in n-propanol at $100 \mathrm{~K}$. $\mathrm{L}=$ total luminescence, $\mathrm{F}=\mathrm{fluorescence,} P=$ phosphorescence. In the higher energy range: solid line, absorption; dashed line, fluorescence excitation; dash-dot line, phosphorescence excitation. The dotted curves indicate the absorption spectra at room temperature. The fluorescence spectrum of III was recorded at $120 \mathrm{~K}$.

difference between fluorescence and phosphorescence excitation spectra was observed also for aniline and dimethylaniline $[26,27]$.

\subsection{Room and intermediate temperature}

Room temperature luminescence of I-III in $\mathrm{n}$-propanol is undetectable in the range of 13500 $\mathrm{cm}^{-1}-25000 \mathrm{~cm}^{-1}$. When lowering the temperature the fluorescence bands of I-III appear. The relatively small Stokes shift, weakly dependent on temperature, indicates that the fluorescence originates from the primarily excited species $\left(b^{*}\right)$. The dependence of the relative fluorescence quantum yield of I-III on temperature is shown in fig. 5.

It was established for many para-substituted dimethylanilines in fluid n-propanol, that the process of TICT state formation at $293 \mathrm{~K}$ is much faster than the other depopulation channels [28-30] and the barriers of the excited state reactions $\left(E_{1}\right)$ are $1000-1200 \mathrm{~cm}^{-1}$ (table 2).

The comparison of the $E_{1}$ values (table 2) with the known activation energies of viscous flow $(1320$ $\mathrm{cm}^{-1}$ for $\mathrm{n}$-propanol [28]) suggests that the TICT formation kinetics of p-cyano and carbonyl derivatives of $\mathrm{N}-, \mathrm{N}$-dimethylaniline in $\mathrm{n}$-propanol is viscosity-controlled. The height of the barrier 
evaluated from the temperature dependence of $\ln \left(\eta / \eta_{0}\right)$ for I in n-propanol $\left(600 \mathrm{~cm}^{-1}\right)$ is evidently less than in the molecules emitting dual fluorescence (table 2).

The lack of TICT fluorescence in I may be caused by:

(1) fast nonradiative process $S_{1} \rightarrow S_{0}$, other than TICT state formation,

(2) intense nonradiative process TICT $\rightarrow \mathrm{S}_{0}$,

(3) nonexistence of the TICT state at lower energy than the primary (planar) excited state $S_{1}$.
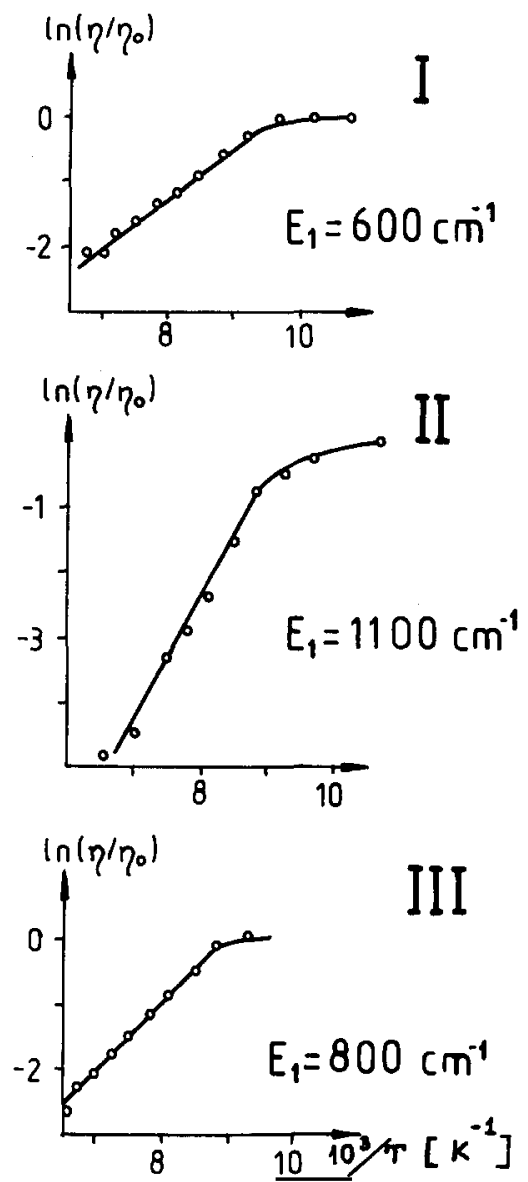

Fig. 5. Dependences of the relative fluorescence quantum yields of I, II and III on temperature in n-propanol. $\eta_{0}$, fluorescence quantum yield at lowest temperature; $E_{1}$, activation energies: $E_{1}(\mathrm{I})=600 \mathrm{~cm}^{-1}, E_{1}(\mathrm{II})=1100 \mathrm{~cm}^{-1}, E_{1}($ III $)$

$$
=800 \mathrm{~cm}^{-1} \mp 100 \mathrm{~cm}^{-1} \text {. }
$$

Table 2

The barriers $\left(E_{1}\right)$ and rate constants of TICT state formation $(\vec{k})$ at room temperature for some derivatives of dimethylaniline in $\mathrm{n}$-propanol

\begin{tabular}{|c|c|c|}
\hline Compound & $\begin{array}{l}E_{1} \\
\left(\mathrm{~cm}^{-1}\right)\end{array}$ & $\begin{array}{l}\vec{k}(293 \mathrm{~K}) \\
\left(\mathrm{s}^{-1}\right)\end{array}$ \\
\hline & $\begin{array}{l}1000 \mp 40 \\
{[28]}\end{array}$ & \\
\hline & $\begin{array}{l}1210 \mp 40 \\
{[28]}\end{array}$ & \\
\hline & & $\begin{array}{l}5 \times 10^{10} \\
{[29]}\end{array}$ \\
\hline & $\begin{array}{l}1190 \mp 70 \\
{[30]}\end{array}$ & $\begin{array}{l}\sim 10^{11} \\
{[30]}\end{array}$ \\
\hline & $\begin{array}{l}1100 \mp 100 \\
{[30]}\end{array}$ & $\begin{array}{l}-10^{11} \\
{[30]}\end{array}$ \\
\hline
\end{tabular}

(1) Kallir observed at $10 \mathrm{~K}$ and $77 \mathrm{~K}$ a double exponential decay of the fluorescence of $I$ in ethanol, characterized by the lifetimes $4.2 \mp 0.2 \mathrm{~ns}$ and $1.1 \mp 0.2 \mathrm{~ns}$, ascribed to two slightly different fluorescence bands [25]. Assuming $k_{\text {ISC }}$ to be temperature-independent, the rate constant of the triplet formation of I at room temperature should be about $10^{+9} \mathrm{~s}^{-1}$. A similar value of $k_{\text {ISC }}$ was found for carbonyl derivatives of dimethylaniline [14] whereas the TICT state formation for cyano and carbonyl derivatives of dimethylaniline is evidently faster (table 2).

(2) Photorotamerisation of excited I to a TICT state should reveal stronger temperature dependence of $\ln \left(\eta / \eta_{0}\right)$ than in the case of II where the reaction is excluded (fig. 5). The opposite effect is observed experimentally.

These facts $(1,2)$ suggest that $I$, in contrast to numerous other p-derivatives of dimethylaniline, does not relax to the TICT state (3). 


\section{Quantum chemical calculations}

In order to investigate the behaviour of the excited electronic states of I upon twisting of the dimethylamino group $\mathrm{N}\left(\mathrm{CH}_{3}\right)_{2}$ or the nitro group $\mathrm{NO}_{2}$ we have performed an INDO/S calculation for different values of the twist angle of these groups. A comparison of the observed and calculated absorption spectra of I-IV is given in fig. 6. Planar molecule: The calculated $\mathrm{S}_{1}$ and $\mathrm{S}_{2}$ transitions correspond to $\mathrm{n}, \pi^{*}$ excitations (fig. 6 , table 3) with electron redistribution mainly localized within the $\mathrm{NO}_{2}$ group (fig. 7). The calculated

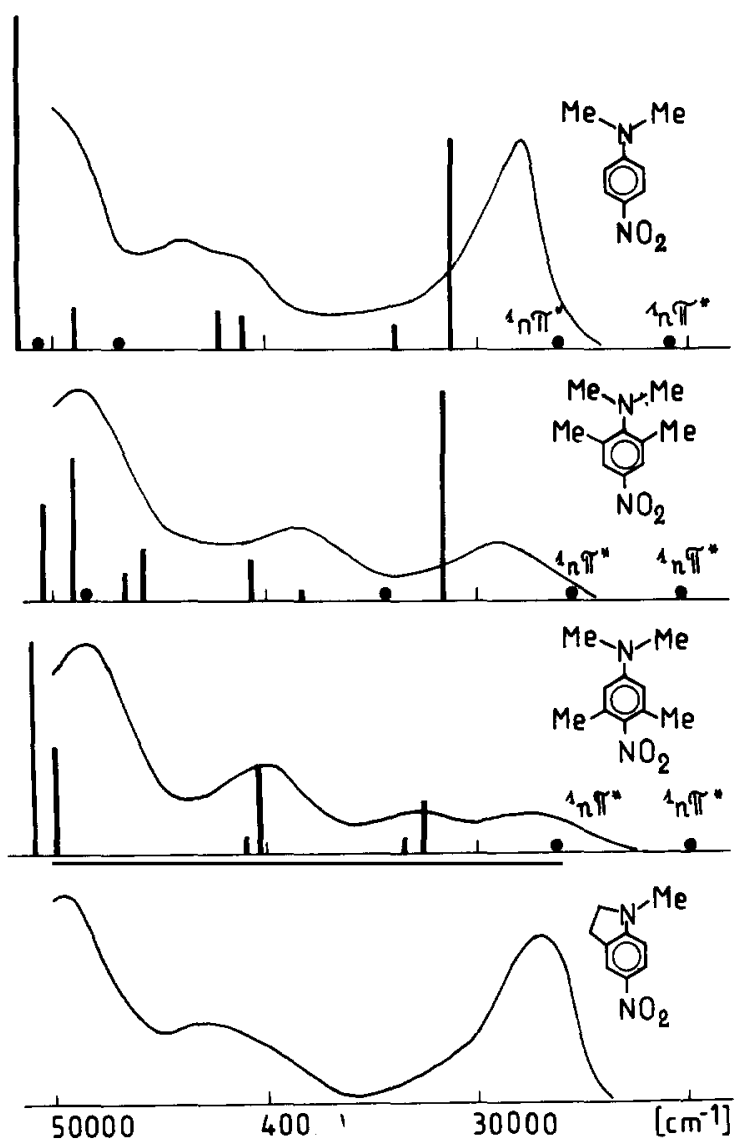

Fig. 6. Room-temperature absorption spectra of I-IV in methylcyclohexane and calculated transitions (geometry A), twist angles $0^{\circ}$ or $60^{\circ}$. Circles indicate that oscillator strengths are smaller than 0.01 . The maxima of the absorption spectra of $I$, III and IV are recorded to the higher energy region in comparison with the data published before [31].
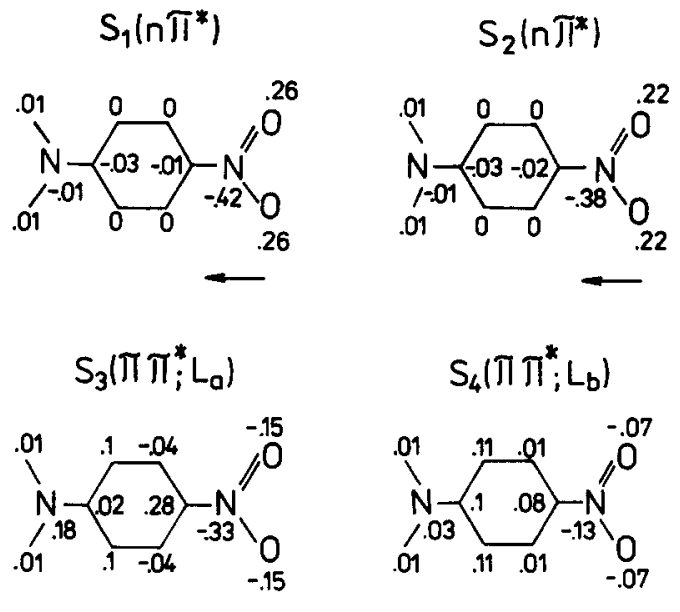

Fig. 7. The changes in electron distribution $\Delta q_{i}$ upon excitation calculated for $S_{1}-S_{4}$ states of planar $I, \Delta q_{i}\left(S_{k}\right)=$ $q_{i}\left(\mathrm{~S}_{k}\right)-q_{i}\left(\mathrm{~S}_{0}\right) ; i$ and $k$ indicate, respectively, the number of the atom and the state. The flow of the negative charge is indicated with an arrow. Charges on the omitted hydrogen atoms are not shown.

energy of the lowest $n \rightarrow \pi^{*}$ transition is evidently lower than the experimental one measured for nitrobenzene [33], while it is a general result obtained within the INDO/S algorithm $[34,35]$ (see, however, that Bigelow et al. [36] succeeded in calculating the lowest $n \pi^{*}$ triplet and singlet states in close agreement with experiment using the CNDO/S-CT method with selected parameter options).

Two $\pi \rightarrow \pi^{*}$ transitions $\left(\mathrm{S}_{0}-\mathrm{S}_{3}, \mathrm{~S}_{4}\right)$ have been computed in the low-energy region which correspond to the ${ }^{1} L_{a}$ and ${ }^{1} L_{b}$ states (figs. 6, 7). The long-axis polarized transition $\mathrm{S}_{0} \rightarrow{ }^{1} \mathrm{~L}_{\mathrm{a}}$ reveals a significant charge transfer contribution from the amino nitrogen to the nitrobenzene moiety. On the contrary, the other, short-axis polarized transition to ${ }^{1} \mathrm{~L}_{\mathrm{b}}\left(\mathrm{S}_{4}\right)$, is almost exclusively localized on the benzene ring. The dependence of the energy on the geometry is observed mainly for the second $\mathrm{n} \pi^{*} \leftarrow \mathrm{S}_{0}$ and ${ }^{1} \mathrm{~L}_{\mathrm{a}} \leftarrow \mathrm{S}_{0}$ transitions (table 3).

Twisted conformers: The results of the INDO/S calculations for the conformers with the planes of $\mathrm{N}\left(\mathrm{CH}_{3}\right)_{2}$ or $\mathrm{NO}_{2}$ substituents perpendicular to the ring are shown in fig. 8 . The ground state rotation energy barriers of the $\mathrm{N}\left(\mathrm{CH}_{3}\right)_{2}$ and $\mathrm{NO}_{2}$ substituents (the same as for p-dimethylamino- 
Table 3

The results of INDO/S calculations for different geometries A and B (see text) and experimental data for planar I molecule; $\epsilon=$ extinction coefficient

\begin{tabular}{|c|c|c|c|c|c|c|c|c|c|}
\hline & \multicolumn{3}{|c|}{ INDO/S (B) } & \multicolumn{3}{|c|}{ INDO/S (A) } & \multicolumn{3}{|c|}{ Experimental data } \\
\hline & \multirow{2}{*}{$\begin{array}{l}E \\
\left(\mathrm{~cm}^{-1}\right)\end{array}$} & \multirow[t]{2}{*}{$\mu[\mathrm{D}]$} & \multirow[t]{2}{*}{$f$} & \multirow{2}{*}{$\begin{array}{l}E \\
\left(\mathrm{~cm}^{-1}\right)\end{array}$} & \multirow[t]{2}{*}{$\mu[\mathrm{D}]$} & \multirow[t]{2}{*}{$f$} & \multirow{2}{*}{$\begin{array}{l}E \\
\left(\mathrm{~cm}^{-1}\right)\end{array}$} & \multirow[t]{2}{*}{$\mu[\mathrm{D}]$} & \multirow{2}{*}{$\frac{\epsilon(\tilde{v})}{\epsilon\left(28100 \mathrm{~cm}^{-1}\right)}$} \\
\hline & & & & & & & & & \\
\hline$\overline{S_{0}}$ & & 9.6 & & & 8.4 & & & $6.9,5.1,5[32]$ & \\
\hline $\mathbf{S}_{1}$ & 19400 & 6.9 & 0 & 20500 & 6.5 & 0 & $29400^{\text {a) }}$ & & a) \\
\hline$S_{2}$ & 22500 & 7.3 & $8 \times 10^{-6}$ & 26100 & 6.9 & $5 \times 10^{-5}$ & & & \\
\hline$S_{3}$ & 27100 & 20.9 & 0.66 & 31200 & 21.3 & 0.48 & 28100 & $15,13,12[32]$ & 1 \\
\hline $\mathrm{S}_{4}$ & 33200 & 13.7 & 0.002 & 33900 & 11.1 & 0.06 & $32200(s)^{b)}$ & & 0.25 \\
\hline$S_{5}$ & 39100 & 17.2 & 0.05 & 41100 & 19.8 & 0.08 & $41200(s)$ & & 0.39 \\
\hline $\mathrm{S}_{6}$ & 42000 & 13.8 & 0.11 & 42700 & 14.7 & 0.09 & $42800(s)$ & & 0.48 \\
\hline$S_{7}$ & 44700 & 6.4 & 0.39 & 46900 & 10.9 & 0.002 & 44300 & & 0.5 \\
\hline $\mathbf{S}_{8}$ & 47400 & 8.6 & 0.003 & 49000 & 6.7 & 0.1 & & & \\
\hline$S_{9}$ & 51600 & 13.9 & $3 \times 10^{-4}$ & 50800 & 9.7 & $4 \times 10^{-4}$ & & & \\
\hline$S_{10}$ & 53600 & 16.5 & 0 & 51600 & 11.4 & 0.78 & $>50000$ & & $>1$ \\
\hline
\end{tabular}

a) $\epsilon=140$ for ${ }^{1} \mathrm{n}, \pi^{*}$ of nitrobenzene [33].

b) $\mathrm{s}=$ shoulder.

benzaldehyde [37]) were taken into account in order to attain correct energy levels of the two twisted conformers in comparison with the planar one. For the planar molecule and for a conformer with the twisted $\mathrm{N}\left(\mathrm{CH}_{3}\right)_{2}$ group the calculated energies, dipole moments and oscillator strengths

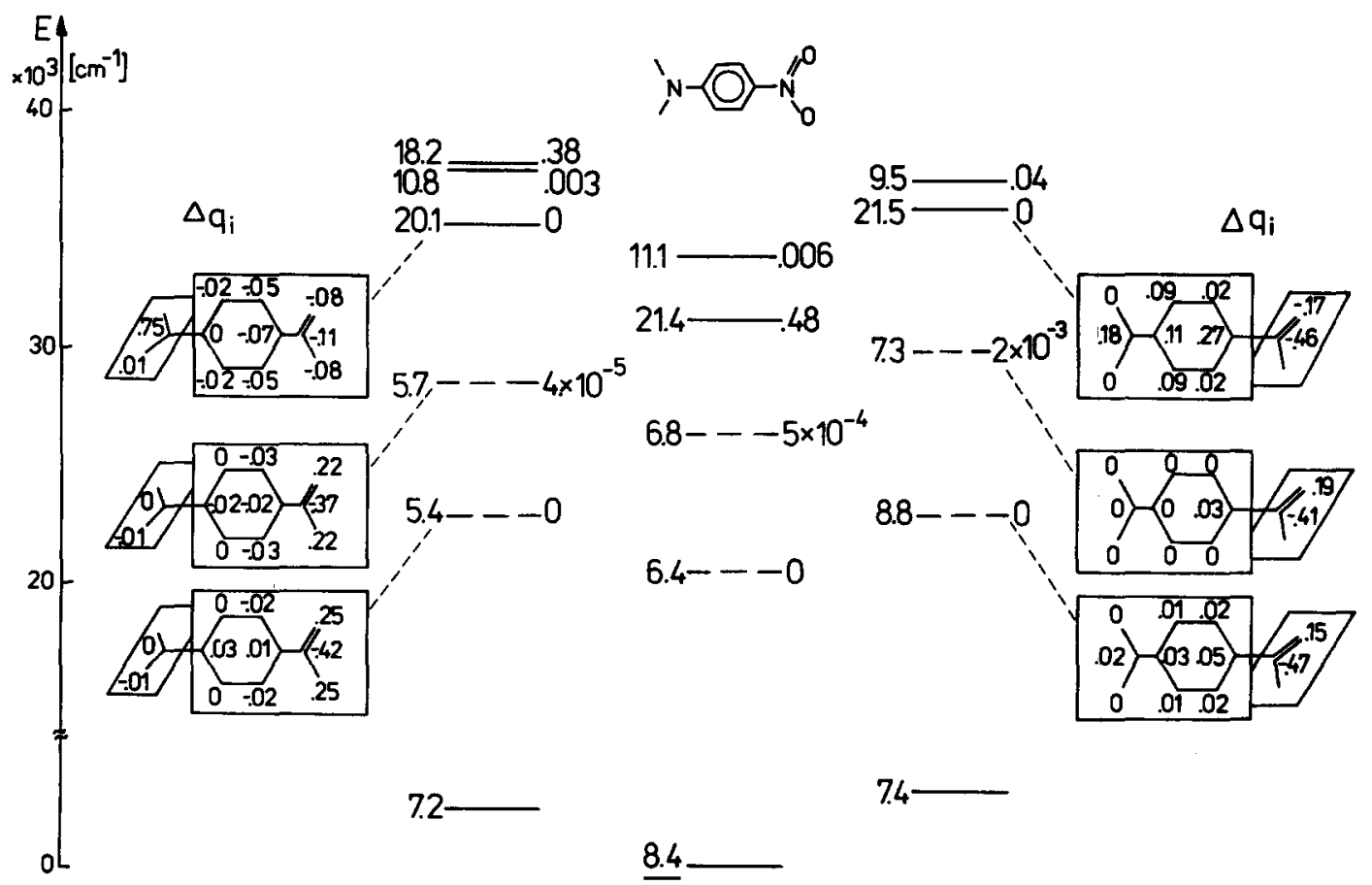

Fig. 8. Scheme of the energy levels of planar molecule I and two twisted conformers calculated by the INDO/S method (geometry A). Numbers of the left side indicate the dipole moments (in Debye units) while the oscillator strengths are shown on the right. $\Delta q_{i}$ are the changes in electron distribution upon excitation, as defined in fig. 7. 
for $\mathrm{n} \rightarrow \pi^{*}$ transitions are similar (fig. 8). Very small oscillator strength and a large dipole moment ( $\mu=20.1$ [D], 0.8 electron transfer between donor and acceptor subunits) of the $S_{3}$ state of the conformer with the twisted $\mathrm{N}\left(\mathrm{CH}_{3}\right)_{2}$ group (fig. 8) corresponds to the TICT model. The TICT state generated by the rotation of the $\mathrm{N}\left(\mathrm{CH}_{3}\right)_{2}$ group is energetically higher, about $4000 \mathrm{~cm}^{-1}$, than the ${ }^{1} L_{a}$ state of a planar molecule. As the TICT emission has been observed mostly in polar solvents, the possibility of energetic stabilisation due to solvation must be taken into account [30]. The calculations gave the same values (within $\pm 10 \%$, depending on geometry) of dipole moments in planar and twisted conformers. Thus, the role of solvent stabilisation does not seem to be important for inversion of these states.

For the conformer with the $\mathrm{NO}_{2}$ group perpendicular to the ring the lowest calculated $\mathrm{n} \rightarrow \pi^{*}$ transition has some admixture of the charge transfer configuration (fig. 8). Consequently, the dipole moment of the state is higher $(\mu=8.8$ [D]) than the dipole moment of the lowest ${ }^{1} n, \pi^{*}$ state of the planar molecule $(\mu=6.4$ [D]). The energies, dipole moments and oscillator strengths of the second ${ }^{1} n, \pi^{*}$ states are similar for the planar and twisted conformer. The lowest ${ }^{1} \pi, \pi^{*}$ state $(\mu=$ $21.5[\mathrm{D})]$ is energetically higher than the lowest ${ }^{1} \pi$, $\pi^{*}$ state of the planar molecule $(\mu=21.4[D])$. Again, from a comparison of the dipole moment values, one can exclude a possibility of the solvent stabilization of the twisted form with respect to<smiles>CN(C)c1ccc(NO)cc1</smiles>

Fig. 9. Formulae of compounds V and VI.

the planar one. In consequence, the TICT formation is highly improbable.

In summary, INDO/S calculations indicate that I after excitation in fluid polar solvents cannot relax to the TICT stage generated by the rotation of neither the $\mathrm{N}\left(\mathrm{CH}_{3}\right)_{2}$ nor $\mathrm{NO}_{2}$ group. This result is consistent with the suggestion of Cowley and Peoples [38] that for strong acceptors, nitrobenzene or s-triazine, the TICT emission cannot be observed.

To check the reliability of the INDO/S method in predicting the energy of TICT stages we performed the calculations for the compound which is known to undergo excited state intramolecular electron transfer - $\mathrm{p}-\mathrm{N}, \mathrm{N}$-dimethylaminoacetophenone (V), [13,14,30,39] (fig. 9).

In this case, the computed energy of the ${ }^{1} L_{a}$ state slightly decreases upon twisting of the electron donor group (table 4, fig. 10). Simultaneously, the value of the dipole moment increases from $\mu=11.5[\mathrm{D}]$ at $0^{\circ}$ to $\mu=14$ [D] at $90^{\circ}$

Table 4

The results of INDO/S calculations (geometry A) and experimental data (from ref. [13]) for planar and twisted molecule $\mathrm{V}$ in n-heptane

\begin{tabular}{|c|c|c|c|c|c|c|c|}
\hline \multicolumn{4}{|l|}{$\mathrm{INDO} / \mathrm{S}$} & \multicolumn{4}{|c|}{ Experimental data [13] } \\
\hline State & $\begin{array}{l}E \\
\left(\mathrm{~cm}^{-1}\right)\end{array}$ & $\mu[\mathrm{D}]$ & $\bar{f}$ & State & $\begin{array}{l}E \\
\left(\mathrm{~cm}^{-1}\right)\end{array}$ & $\mu[\mathrm{D}]$ & $\epsilon$ \\
\hline$\overline{S_{0}}$ & & 5.3 & & $\mathrm{~S}_{0}$ & & $5.6^{\text {a) }}$ & \\
\hline$S_{1}\left(n, \pi^{*}\right)$ & 25700 & 2.2 & $4 \times 10^{-5}$ & ${ }^{1} \mathrm{n}, \pi^{*}$ & 28500 & & 150 \\
\hline$S_{2}\left(L_{b}\right)$ & 34300 & 6.6 & 0.019 & $\mathrm{~L}_{\mathrm{a}}$ & 31000 & $13^{\text {a) }}$ & 29000 \\
\hline $\mathrm{S}_{3}\left(\mathrm{~L}_{\mathrm{a}}\right)$ & 38100 & 11.5 & 0.56 & $\mathrm{~L}_{\mathrm{b}}$ & 32000 & & \\
\hline TICT & 35400 & 14 & $1 \times 10^{-6}$ & TICT & $28000-33000^{b)}$ & & \\
\hline
\end{tabular}

a) For p-dimethylaminobenzaldehyde [32].

b) $18000 \mathrm{~cm}^{-1}$ fluorescence maximum in acetonitrile [13]; the extrapolation of the solvatochromic correlation to nonpolar solvent leads to the values $28000-33000 \mathrm{~cm}^{-1}$ depending on the model. 


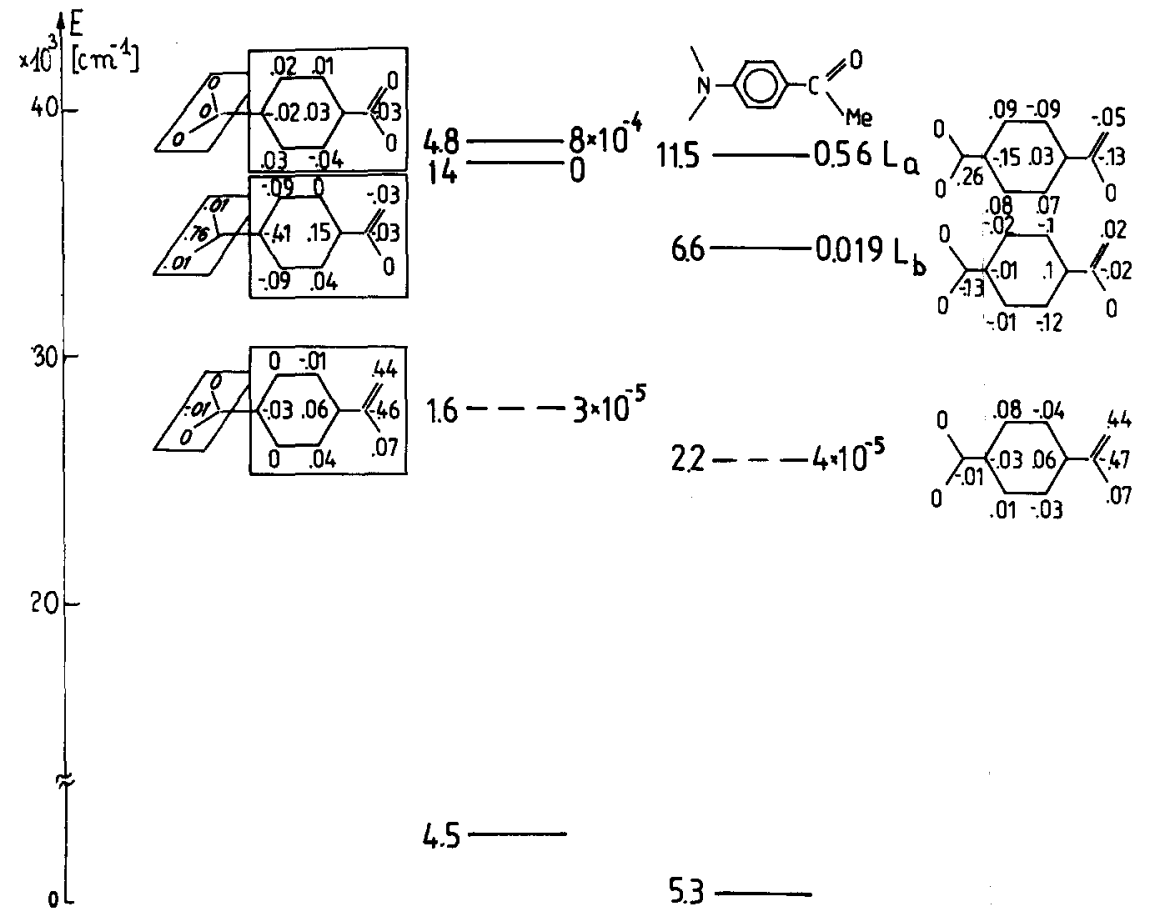

Fig. 10. Scheme of the energy levels of planar molecule $\mathrm{V}$ and twisted conformer $\left(\mathrm{N}\left(\mathrm{CH}_{3}\right)_{2}\right)$ calculated by the INDO/S method (geometry A). Numbers on the left side indicate dipole moments (in $\mathrm{D}$ units) while oscillator strengths are shown on the right. $\Delta q_{\text {, }}$ are as defined in fig. 7.

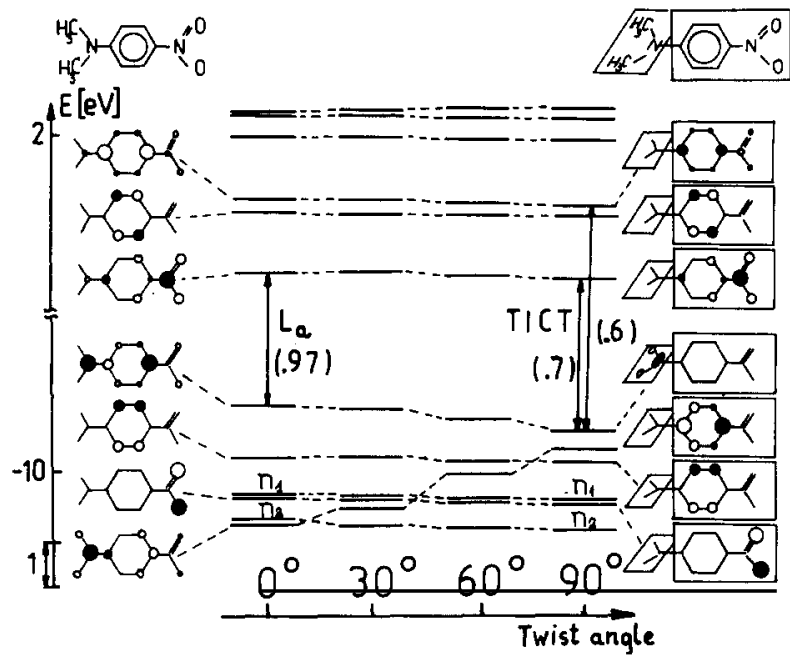

Fig. 11. Scheme of the molecular orbitals of planar molecule I and the conformer with the twisted $\mathrm{N}\left(\mathrm{CH}_{3}\right)_{2}$ group calculated by INDO/S method (geometry $\mathrm{A}$ ).

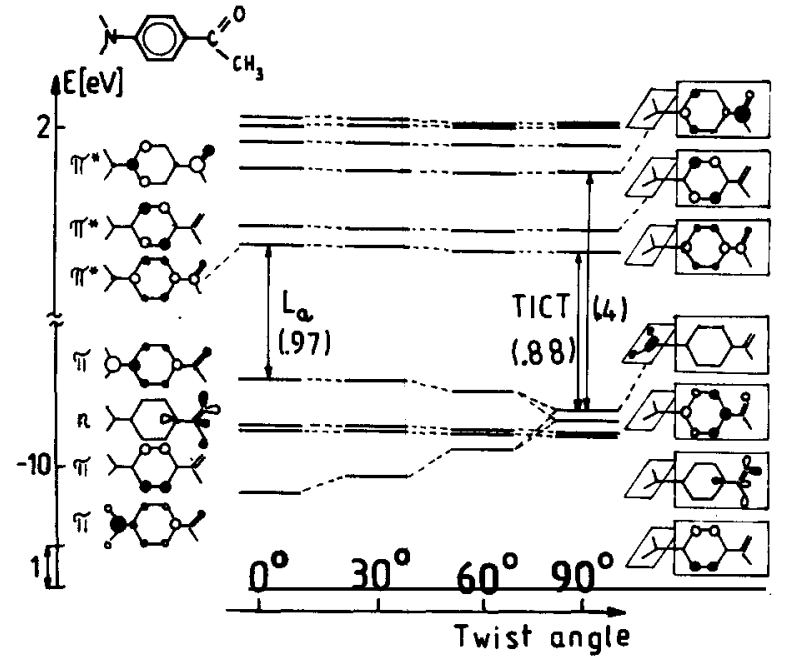

Fig. 12. Scheme of the molecular orbitals of planar molecule $V$ and the conformer with the twisted $\mathrm{N}\left(\mathrm{CH}_{3}\right)_{2}$ group calculated by INDO/S method (geometry A). 
Table 5

The results of INDO/S calculations for I and $V$ for various angles of twisting of the dimethylamino group with respect to the phenyl ring, $c_{i}$ the contribution of the " $i$ " configuration to the wavefunction of the ${ }^{1} \mathrm{~L}_{\mathrm{a}}$ state. $J$ and $K$ are Coulomb and exchange integrals. The $2 K$ value for the planar molecule is equal to the singlet-triplet separation, for the TICT state $K$ should be zero [7]

\begin{tabular}{|c|c|c|c|c|c|c|c|c|}
\hline \multirow{2}{*}{$\begin{array}{l}\text { Twist } \\
\text { angle }\end{array}$} & \multicolumn{4}{|l|}{ I } & \multicolumn{4}{|l|}{$\mathrm{V}$} \\
\hline & $\overline{c_{i}}$ & $\begin{array}{l}|J-2 K| \\
\left(\mathrm{cm}^{-1}\right)\end{array}$ & $\begin{array}{l}|2 K| \\
\left(\mathrm{cm}^{-1}\right)\end{array}$ & $\begin{array}{l}|J| \\
\left(\mathrm{cm}^{-1}\right)\end{array}$ & $\overline{c_{i}}$ & $\begin{array}{l}|J-2 K| \\
\left(\mathrm{cm}^{-1}\right)\end{array}$ & $\begin{array}{l}|2 K| \\
\left(\mathrm{cm}^{-1}\right)\end{array}$ & $\begin{array}{l}|J| \\
\left(\mathrm{cm}^{-1}\right)\end{array}$ \\
\hline $0^{\circ}$ & 0.971 & 25400 & 4000 & 21400 & 0.969 & 26900 & 7000 & 19900 \\
\hline $30^{\circ}$ & 0.965 & 25200 & & & 0.958 & 27100 & & \\
\hline $60^{\circ}$ & 0.921 & 24800 & & & 0.890 & 28000 & & \\
\hline $90^{\circ}$ & 0.744 & 23100 & 0 & 23100 & 0.884 & 30800 & 0 & 30800 \\
\hline
\end{tabular}

which additionally should stabilize the TICT state in polar solvents.

Thus, the calculations predict two opposite reactions of the ${ }^{1} \mathrm{~L}_{\mathrm{a}}$ state energy on the twisting of the dimethylamino group in the two molecules (figs. 8, 10). The reason for this may be found upon inspection of the factors contributing to the transition energy. For a single configuration corresponding to the electron jump from an orbital " $i$ " to an orbital " $k$ " this value is given by:

$$
\Delta E=\epsilon_{k}-\epsilon_{i}-J_{i k}+2 K_{i k}
$$

$\epsilon_{j}$ denotes the energy of the orbital " $j$ ", $J$ and $K$ are the Coulomb and exchange integrals, respectively.

In both molecules, the ${ }^{1} \mathrm{~L}_{\mathrm{a}}$ state is very well described by a single configuration corresponding to the promotion of an electron from the highest occupied to the lowest unoccupied orbital (figs. 11, 12). Upon twisting of the dimethylamino group, the orbital energy difference evolves similarly in both molecules. It is the opposite behaviour of the $(-J+2 K)$ terms which differentiates between I

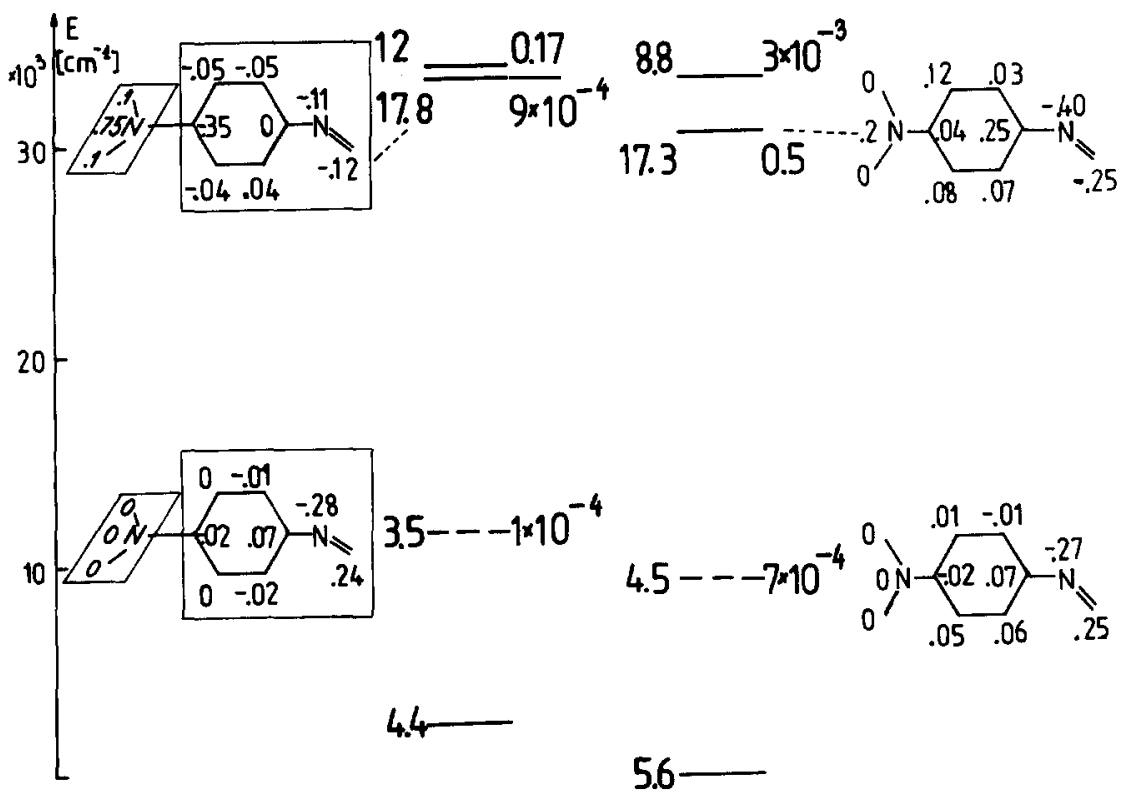

Fig. 13. Scheme of energy levels of planar molecule VI and conformer with twisted $\mathrm{N}\left(\mathrm{CH}_{3}\right)_{2}$ group calculated by the INDO/S method (geometry A). Numbers on the left side indicate the dipole moments (in D units) while oscillator strengths are shown on the right. $\Delta q_{i}$ are as defined in fig. 7. 
Table 6

The results of INDO/S calculations (geometry A) and experimental data for the planar molecule VI

\begin{tabular}{|c|c|c|c|c|c|c|}
\hline \multicolumn{3}{|c|}{$\overline{\mathrm{INDO} / \mathrm{S}}$} & \multicolumn{4}{|c|}{ Experimental data [41] } \\
\hline $\begin{array}{l}\bar{E} \\
\left(\mathrm{~cm}^{-1}\right)\end{array}$ & $\mu[\mathrm{D}]$ & $f$ & $\begin{array}{l}E \\
\left(\mathrm{~cm}^{-1}\right)\end{array}$ & $\mu[\mathrm{D}]$ & & $\bar{\epsilon}$ \\
\hline & 5.6 & & \multicolumn{4}{|c|}{$6.9,6.5[32]$} \\
\hline 9300 & 4.5 & $1 \times 10^{-4}$ & 13790 & & & 48 \\
\hline 30600 & 17.3 & 0.5 & 25200 & 13 & [32] & 31000 \\
\hline 33200 & 8.8 & 0.003 & 32790 & & & 3600 \\
\hline 40500 & 15.8 & 0.16 & 37740 & & & 6000 \\
\hline
\end{tabular}

and V (table 5) leading to the stabilization of the transition energy in the latter and to destabilization in the former.

The different fluorescence bands observed for amino derivatives of coumarine have been also explained in terms of the different Coulomb interaction in excited states depending on the different position of the substitution of the $\mathrm{NH}_{2}$ group [40].

The results of calculations show that one should be careful while trying to estimate the TICT energy from thermodynamical considerations presented in the beginning of this work, the Coulomb stabilisation energy may widely differ in specific cases (in the first approximation [8] it has been taken as $-e^{2} / \epsilon r$ where $r$ was the idealized mean distance of charge separation, $\epsilon$ the macroscopic dielectric constant of the solvent).

We have also made the calculations for a molecule containing a nitroso group (VI) as the electron acceptor. Nitrosobenzene is a stronger acceptor $\left(E_{1 / 2}^{\text {red }}=-0.81 \mathrm{~V}\right.$ [9] $)$ than nitrobenzene. Similarly to I a destabilization of the TICT state for the twisted conformer with respect to the $\mathrm{L}_{\mathrm{a}}$ state of the planar molecule was calculated (fig. 13), which leads to a prediction that this compound probably would not reveal a TICT fluorescence.

\section{Conclusions}

The experimental results and quantum chemical calculations demonstrate that I after excitation in fluid polar solvent does not relax to the TICT state generated by the rotation of the $\mathrm{N}\left(\mathrm{CH}_{3}\right)_{2}$ or $\mathrm{NO}_{2}$ group.

\section{Acknowledgements}

We are deeply grateful to Professor Z.R. Grabowski for helpful discussions and critical reading of the manuscript. We also wish to thank Professor Dietrich Döpp (Duisburg University) for the gift of $\mathrm{p}$-nitro-N,N-dimethylaniline, and Dr. Jan Maurin for the gift of N,N-2,6-tetramethyl-4-nitroaniline. The work was partly done under Polish research project CPBP 01.19.

\section{References}

[1] E. Lippert, W. Lüder and H. Boos, in: Advances in Molecular Spectroscopy, ed. A. Mangini (Pergamon, Oxford, 1962) p. 443.

[2] O.S. Khalil, R.H. Hofeldt and S.P. McGlynn, J. Lumin. 6 (1973) 229.

[3] E.A. Chandross, in: The Exciplex, eds. M. Gordon and W.R. Ware (Academic Press, New York, 1975) p. 187.

[4] R.J. Visser and C.A.G.O. Varma, J. Chem. Soc. Faraday II 76 (1980) 453.

[5] E.M. Kosower and H. Dodiuk, J. Am. Chem. Soc. 98 (1976) 924.

[6] W. Baumann, Z. Naturforsch. 36a (1981) 868.

[7] Z.R. Grabowski, K. Rotkiewicz, A. Siemiarczuk, D.J. Cowley and W. Baumann, Nouv. J. Chim. 3 (1979) 443.

[8] Z.R. Grabowski and J. Dobkowski, Pure Appl. Chem. 55 (1983) 245.

[9] L. Meites and P. Zuman, Electrochemical Data (Wiley, New York, 1974).

[10] J. Smagowicz, PhD Thesis (Inst. Phys. Chem., Warsaw, 1974).

[11] J. Herbich, Z.R. Grabowski, H. Wójtowicz and K. Golankiewicz, J. Phys. Chem. 93 (1989) 3439.

[12] H. Beens and A. Weller, Acta Phys. Polon. 34 (1968) 593.

[13] E. Kirkor-Kaminska, PhD Thesis (Inst. Phys. Chem., Warsaw, 1980).

[14] J. Dobkowski, Z.R. Grabowski, E. Heumann, D. Khechinashivili, B. Kozankiewicz, W. Kühnle and J. Sepiol, Proc. Int. Symp. on Molecular Luminescence and Photophysics: "Half a Century of the Jablonski Diagram", Torun (1986) p. 81.

[15] F. Fournier, J. Berthelof and Y.L. Pascal, Can. J. Chem. 61 (1983) 2121.

[16] D.J. Cowley and P.J. Healy, Proc. Roy. Irish Acad. 77B (1977) 397.

[17] (a) D. Döpp and B. Gerding, IX. Symp. IUPAC de Photochimie, France, 1982;

(b) D. Dopp, Chem. Ber. 104 (1971) 1043;

(c) D. Döpp, in: Topics in Current Chemistry, Vol. 55, ed. F. Boschke (Springer, Berlin, Heidelberg, New York, 1975) p. 49. 
[18] (a) H.M. Fitch, in: Organic Syntheses, Coll. Vol. III, ed. E.C. Horning (Wiley, London, 1955) p. 658; (b) R. Garner, Tetrahedron Lett. 2 (1968) 221

[19] J. Maurin and T.M. Krygowski, J. Mol. Struct. 158 (1987) 359.

[20] J. Jasny, J. Lumin. 17 (1978) 149.

[21] J. Ridley and M.C. Zerner, Theor. Chim. Acta 32 (1973) 111.

[22] A.W. Salotto and L. Brunelle, J. Chem. Phys. 53 (1970) 333.

[23] R.W.G. Wyckoff, ed., Crystal Structure, Vol. 6 (Interscience, New York, 1969) pp. 122, 355.

[24] (a) M. Kasha and R. Rawls, Photochem. Photobiol. 7 (1968) 561 ;

(b) C. Seliskar, O. Khalil and McGlynn, in: Excited State Vol. 1, ed. E.C. Lim (Academic Press, New York, London, 1974) p. 232.

[25] A.J. Kallir, G.W. Suter and U.P. Wild, J. Phys. Chem. 91 (1987) 60.

[26] C. Dubroca, Chem. Phys. Lett. 15 (1972) 207.

[27] C. Dubroca and P. Lozano, ibid 24 (1973) 49.

[28] Z.R. Grabowski, K. Rotkiewicz, W. Rubaszewska and E. Kirkor-Kaminska, Acta Phys. Polon. A54 (1978) 767.

[29] Y. Wang, M. McAuliffe, F. Novak and K.B. Eisenthal, J. Phys. Chem. 85 (1981) 3736.
[30] J. Dobkowski, E. Kirkor-Kamińska, J. Koput and A. Siemiarczuk, J. Lumin. 27 (1982) 339.

[31] M. Godfrey and J.N. Murrell, Proc. Roy. Soc. Ser. A 278 (1964) 71.

[32] W. Liptay, Excited States, Vol. 1, ed. E.C. Lim (Academic Press, New York, 1974) p. 196.

[33] S. Nagakura, M. Kojima and Y. Maruyama, J. Mol. Spectr. 13 (1964) 174

[34] O.S. Khalil, C.J. Seliskar and S.P. McGlynn, J. Mol. Spect. 70 (1978) 74.

[35] T.P. Carsey, G.L. Findley and S.P. McGlynn, Am. Chem. Soc. 101 (1979) 4502.

[36] R.W. Bigelow, H.J. Freud and B. Dick, Theoret. Chim. Acta (Berlin) 63 (1983) 117.

[37] T.B. Grindley and A.R. Katritzky, J. Chem. Soc. Perkin II, 5 (1975) 443.

[38] D.J. Cowley and A.H. Peoples, J. Chem. Soc. Chem. Commun. (1977) 352.

[39] Z.R. Grabowski, J. Dobkowski and W. Kühnle, J. Mol. Struct. 114 (1984) 93.

[40] W. Rettig and A. Klock, Can. J. Chem. 63 (1985) 1649.

[41] N.J. Bunce, Chem. Phys. Lett. 59 (1978) 66. 